Nataša Zrilić 1

Davor Širola ${ }^{2}$

\title{
Regional Development Through European Economic Interest GroupINg [EEIG]
}

\begin{abstract}
:
Regional Policy is the European Union's main investment policy. It targets all regions and cities in the EU in order to support job creation, business competitiveness, economic growth, sustainable development, and improve citizens' quality of life. The most recent territorial-cohesion concept employed by European institutions - the macroregional strategies, currently involves EU strategy for the Baltic Sea Region, Danube Region and Adriatic-Ionian Region. Therefore Croatia, as a new member of the EU, should devote special attention to regional development. The new Croatian Act on Regional Development aims to promote partnership as a key dimension of regional planning. The Act also introduces a new category of urban agglomerations which confirms the developmental role of the four largest cities in the Republic of Croatia - Zagreb, Split, Rijeka and Osijek.

The involvement of private business sector in
\end{abstract}

\section{Keywords:}

regional development, European Economic Interest Grouping [EElG], entrepreneurship

\section{Author's data:}

${ }^{1}$ Nataša, Zrilič, PhD In Economy, Senior Adviser to the Mayor, Expert for Development \& Economy, Korzo 16, Rijeka, E-mail: natasa.zrilic@rijeka.hr,

${ }^{2}$ Davor, širola, mag. oec. spec., lecturer, Veleučiliš̈te Rijeka, Vukovarska 58, Rijeka, E-mail: davor.sirola@veleri.hr International Journal - VALLIS AUREA • Volume 1 • Number 2 • Croatia, December 2015 UDK332:658(4); D01 10.2507.IJVA.1.2.10.22

regional development planning can contribute to increasing employment and investment. Also, companies can contribute to the entrepreneurial dimension of regional projects.

Setting up a European Economic Interest Grouping [EEIG], represents one of the possibilities for new entrepreneurial projects development at the regional level. This form allows the cooperation between entrepreneurs and other stakeholders of regional development. Experience has shown that the various sectors implement the EElG. In the Republic of Croatia it is a new topic, but certainly in the future there will be more such initiatives.

The purpose of this paper is to examine the role of EElG in the European Union regional development context. The main objective was to point out the advantages and risks of membership in the EElG and to discuss possible impact of involvement in establishing an EElG for different Croatian partners. 


\section{Introduction}

Europe 2020 strategy puts forward three mutually reinforcing priorities: smart, sustainable and inclusive growth. This is an agenda for all Member states, as well as for candidate countries in the future. Eu regional policy supports the delivery of Europe 2020 strategy.

The beginning of 2015 marks inception of new regional policy in the Republic of Croatia, so all legal novelties are covered in this paper.

As the European Economic Interest Grouping [in short: EElG], represents the main focus of analysis of this paper. Methodology applied include comparison of EU legal solutions and Croatian legal framework in order to determine if EElG can facilitate and invigorate regional potential and partnerships, as well as to examine possible advantages and risks for Croatian partners involvement into EElG partnerships. Assessment of risks of joining the EElG for potential Croatian partners, was conducted through case study analysis of an actual, recent initiative for EElG formation.

This paper is organised in two main segments. First, the regional development and macro-region strategies were explained lsections 2 and 3]. Second, the EElG issues were analysed throughout the EU and Croatian legal frameworks and experiences, as well as first-hand examining an Italian EEIG initiative [sections 4, 5,6 and 7], followed by conclusion.

Importance of regional development in $\mathrm{EU}$ and Republic of croatia

Back in 1980, statistical office of the European Community established NUTS 1, 2 and 3, governing units, as a geocode standard for referencing the administrative divisions of countries for statistical purposes.

According with main criteria (population size) thresholds are:

- NUTS 1 - minimum 3 - maximum 7 million citizens

- $\quad$ NUTS 2 - minimum 0,8 - maximum 3 million citizens

- $\quad$ NUTS 3 - minimum 0,15 - maximum 0,8 million citizens

- $\quad$ LAU1 and LAU 2 - less than 0,15 million citizens Considering the population size in some member states, clearly not all states include all levels, but only one or two NUTS levels, as shown on Map 1, for Croatia.

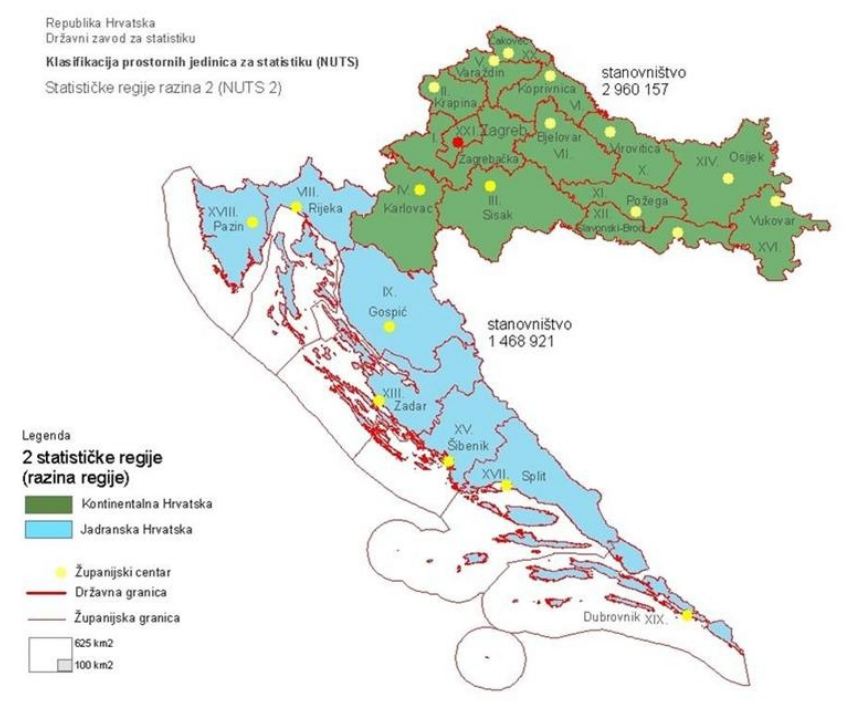

Map 1. Statistical NUIS 2 regions of the Republic of Croatia 
Croatian NUTS 2 regions differ mostly by population size [as shown on Map 1.], with 1.468.921 citizens in Adriatic Croatia and 2.960.157 in Continental Croatia], while the levels of GDP $p / c$ are almost identical (62,1\% of EU27 average in Adriatic Croatia and 64,1\% in Continental Croatia]. There are none LAU 1 level regions determined in Croatia, while cities and municipalities represent LaU 2 Ievel.

Considering administrative-territorial organization and regionalization of croatia, well thought regional policy is of the utmost importance. An essential priority of regional policy is about ensuring access and equal development opportunities for all, throughout the lifecycle and every region of the country, which implies close cooperation of all governance levels Icentral, regional and locall, academic and scientific organizations, social partners and civil society organizations. [1]

Partly, as a consequence of war repercussions and lack of political readiness, before the beginning of EU accession process, the level of fiscal and management decentralization in croatia was very low.

The Act on regional development, which preceded the strategy on regional development of the Republic of Croatia, was adopted during the process of Iegislation harmonization with Acquis. [2] The Act regulates the main objectives and governing principles of regional development, as well as planning documents, governing bodies, method of local development level assessment and the procedures of regional policy implementation reporting. The Act also contributed to improving the system of governing the regional development, especially regarding vertical objectives conerence and better cooperation of all sector involved.
One of the most important principles of regional development involves strategic planning implementation, which imply adopting and execution of long-term planning documents. The Act on regional development defines the planning documents of regional development, with the Strategy on regional development of the Republic of Croatia on the supreme level.

After perennial arrangements croatian Government has enacted the strategy on regional development of the Republic of Croatia [2011.-2013.], in June, 2010. Strategy represents an integral part of development planning process, which ultimate goal is to contribute to overall socio-economic development, by creating favourable preconditions for improving place competitiveness and exploiting the development potentials of all counties, regions, areas of special national concern and border areas, in accordance with the sustainable development principles. [3]

By the end of 2014 a new Act on regional development was passed. This Act much closely reflects the EU reformed regional policy 2014 2020.[4] Important novelties of this Act include establishing four urban agglomerations lagreb, Rijeka, Split and OsijekJ, following the demands of actual EU regional approach which recognized development potential and strong influence of urban centres. The impact of urban agglomerates encompasses wide range of areas and sectors Itransport, infrastructure, health, education, culture and other], especially in the field of human resource - knowledge potentials.

The purpose of urban agglomerations is to synchronize the strategic development. It means that agglomeration objectives must comply with Europe 2020 priorities. As agglomerations are obligated to generate their strategic documents, 
following the procedure which involves Partnership Council, implementation body constituted of numerous members from different sectors, often with different, even conflicting interests, coordinating and harmonizing all aspects becomes quite challenging.

The Act on regional development have also stipulated the role of development agencies on all governing levels, which is another novelty in croatia, especially considering circumstances with strong opponents to decentralization of governance and diminishing central control of the whole system. The new role of agencies is different, as they become an extension of public administration system, more flexible for coordinating numerous activities with other partners.

\section{The role of EU 'macro-regions'}

Considering administrative-territorial organization of Croatia, well thought regional policy is of the utmost importance. Furthermore, EU encourages the formation of macro-regions, as a part of its regional policy, following recognized diversities between EU countries, as well as diversities between cross-national Eu regions, which are considered as valuable EU development resources.

A Macro-Regional strategy is an integrated framework endorsed by the European Council, which may be supported by the European structural and Investment Funds among others, to address common challenges faced by a defined geographical area relating to Member states and third countries located in the same geographical area which thereby benefit from strengthened cooperation contributing to achievement of economic, social and territorial cohesion. The EU has put in place 3 strategies, covering several policies, which are targeted at a macro-region:

- The EU Strategy for the Baltic Sea Region [adopted in 2009.],

- The EU strategy for the Danube Region Ladopted in 2011],

- The EU Strategy for the Adriatic and Ionian Region [adopted Nov. 2014).

- Main characteristics and flagship projects of these macro-regions are listed below. [5]

- $\quad$ Baltic Sea Region [85 million inhabitants]

- The EU Strategy for the Baltic Sea Region [EUSBSR] brings together 8 Member states [Sweden, Denmark, Estonia, Finland, Germany, Latvia, Lithuania, and Poland]. The strategy also welcomes cooperation with neighbouring countries including Russia and Norway.

- Some flagship projects:

- Baltic Deal working with farmers to help reduce nutrient losses from farms, and maintain production and competiveness.

- Efficient, Safe and Sustainable Traffic at Sea (Efficient Sea) making the Baltic Sea Region a pilot region for e-Navigation, by developing and testing infrastructure and services for eNavigation, and sharing good practice widely.

- Baltic Manure turning manure from an environmental problem into an opportunity for business innovation. The project is producing renewable energy and organic fertilisers.

- BSR stars aims to boost regional competitiveness and growth with transnational research and innovation links: tackling common challenges in areas like health, energy and sustainable transport.

Danube region [115 million inhabitants]

- $\quad$ The EU Strategy for the Danube Region [EUSDR] covers 9 EU countries (Germany, Austria, Hungary, Czech Republic, Slovak Republic, Slovenia, Bulgaria, Romania and Croatial and 5 non-EU countries SSerbia, Bosnia and 
Herzegovina, Montenegro, Ukraine and Moldova].

Projects include:

- The co-operative approach has helped to complete the Vidin-Calafat Bridge between Bulgaria and Romania - a vital link on a key priority route of the Trans-European Transport Network (TEN-T). The bridge is only the second one along the $630 \mathrm{~km}$ river section of the border.

- The Danube Shipwreck Removal project aims to remove shipwrecks from the Danube, Sava and Tisa in Serbia, Romania and Bulgaria improving navigation and ecological conditions.

- The Danube Region Business Forum provides an important networking platform for over 300 SMEs. It encourages business-to-business meetings, and supports links with knowledge providers such as research institutes and universities.

- Work has started to create a Danube Research and Innovation Fund, pooling national and regional funds, building on the experiences of the BONUS programme in the Baltic Sea Region.

- The Danube Flood risk project promotes cooperation methods with 19 institutions in 8 Danube countries, sharing databases and flood mapping. The European Flood Awareness System (EFAS) is carrying out complementary work.

Adriatic and Ionian Region (70 million inhabitants)

- A high-level conference in Brussels, on 18 November 2014, launched the Eu strategy for the Adriatic and Ionian Region [EUSAIR]. Participating countries are four EU Member States (Croatia, Greece, Italy, and Slovenia) and four non-EU Countries (Albania, Bosnia and Herzegovina, Montenegro, Serbia].

Four pillars:
- Pillar 1: Blue Growth Icoordinators: Greece and Montenegro]; the specific objectives for this pillar are: to promote research, innovation and business opportunities in blue economy sectors; to adapt to sustainable seafood production and consumption and to improve sea basin governance. To achieve the abovementioned objectives, Pillar 1 will focus on three topics: blue technologies, fisheries and aquaculture and maritime and marine governance and services.

- Pillar 2: connecting the region Icoordinators: Italy and serbia]. The specific objectives for this pillar are: to strengthen maritime safety and security and develop a competitive regional intermodal port system; to develop reliable transport networks and intermodal connections with the hinterland, both for freight and passengers and to achieve a wellinterconnected and well-functioning internal energy market supporting the three energy policy objectives of the EU - competitiveness, security of supply and sustainability. To achieve these objectives, the pillar will focus on three topics: maritime transport, intermodal connections to the hinterland and energy networks.

- Pillar 3: environmental quality Icoordinators: Slovenia and Bosnia and Herzegovina]. The specific objectives for this pillar are: to ensure a good environmental and ecological status of the marine and coastal environment; to contribute to the goal of the EU Biodiversity strategy and to improve waste management by reducing waste flows to the sea and, to reduce nutrient flows and other pollutants to the rivers and the sea. Iwo topics are identified as pivotal in relation to environmental quality in the Adriatic-lonian Region: the marine environment and transnational terrestrial habitats and biodiversity. 
- Pillar 4: sustainable tourism Icoordinators: Croatia and Albania). The specific objectives for this pillar are: diversification of the macroregion's tourism products and services along with tackling seasonality of inland, coastal and maritime tourism demand and improving the quality and innovation of tourism offer and enhancing the sustainable and responsible tourism capacities of the tourism actors across the macro-region. To achieve the above mentioned objectives the pillar will focus on two topics: diversified tourism offer and sustainable and responsible tourism management (innovation and quality].

The sea is one of Earth's most valuable natural resources, large eco-system with different natural resources (fish, waves, flux and reflux of the tides], transport, tourism and mining opportunities, which could easily be compromised due to ship accidents and pollutions, for example. Therefore, a constant cooperation is essential for prevention where EUSAIR enables systematic sustainable approach in tackling of all important issues together (for example: monitoring and waste control, development of appropriate technologies for waste removal and recycling], with other members and with synergy effects.

The Adriatic and Ionian Region and the Danube Region are of utmost importance for Croatian future development. The possibility of incorporating Croatian large projects ffrom transport and ecology in Adriatic to irrigation and flood prevention in Slavonia], into these macro-regions, could become great opportunity, as the projects might be realized together with other macro-regions member countries. Large Croatian cities could also benefit from additional Eu-funding for city projects, as well as from universities development.
The priorities should be research and innovations, accompanied by capacity building and development of small and medium entrepreneurs in order to ensure the systematic exploitation of sea as an economic resource and additional employment. Furthermore, new technologies and innovation should be emphasized, especially regarding management, protection, rescue, waste collecting and processing, research and presentation of underwater culture for public and tourism purposes. Member countries of the EUSAlR project, should strive to achieve results in the field of strategic planning, methodology development and synergy effects from joint management and monitoring systems.

Above mentioned can be summarize by pointing out several critical issues. First, the new Act on regional development (from 2014), has stipulated the objectives and principles for regional development. It has also emphasized significant differences regarding achieved regional development level. Second, Croatian regional development projects lespecially large infrastructure projects], should be prepared coherently with priorities of macro-regions in order to achieve synergy effects on EU level, not just with better use of available Eu-funds in mind.

\section{European Economic Interest Grouping - EElG}

Back in 1985 the Council of the European Communities, has adopted the Council Regulation (EEC) No 2137/85 (in short: Regulation), which determinate the European Economic Interest Grouping (EEIG].[6] According to this Regulation the purpose of EElG shall be to facilitate or develop the economic activities of its members and to improve or 
increase the results of those activities. Interesting fact about this Regulation is that it hasn't been altered in any way, since its adoption.

An EElG must comprise at least two subjects Icompanies, firms, other legal bodies or natural person], which have their central administrations in different Member states. An EElG whose official address is in any part of the EU can act throughout the EU, purely on the strength of the Regulation. The law of the state in which an EElG has its official address is applicable to the contract for the formation of a grouping and to its internal organization.

The conditions of admission or withdrawal from membership of an EElG are defined by EElG Statute (contract for the formation) and the Regulation. The EEla bodies are the members acting collectively and the manager or managers. Although the Regulation defines all elements and the procedure of establishing and acting of an EElG, the founders have open possibility to regulate all necessary issues, by the statute of an EEIG.

The Regulation prescribes that an EElG does not necessarily have to be formed with capital. Members are free to use alternative means of financing. The programme of an EElG, as well as costs of manager[S], can be financed from membership fees. The founders of an EElg have right to elect and control the manager of an EElG. Founding members usually have more rights than new members, including formulating and adopting the statute of an EElG, but new members can participate in joint projects and thereby promote their own goals. [7]

EElG can employ members from several Member states, but Regulation has limited its number to 500 persons to avoid management difficulties. EEIG is an organization with combined characteristics of a business company and non- governmental organizations [NGO's]. Regarding the membership issues and the procedures for decision adoption, EEIG follows the NGO's approach, but profit distribution principles and management style is much more business-like. This type of organization originally emerges from French law, but doesn't have tradition of application in all EU countries and all national legal frameworks.

Therefore it can be concluded that EElG represents a specific model which can be used to pursue some entrepreneurial and social objectives within the territory of several Member states. The essence of EElG establishment encompasses development of joint projects and their co-financing with EU structural funds.

\section{The role of EElG and the new possibilities of regional development}

The European Commission (EC) has recognized the leading role of cities in fostering regional development and consequently allocated large amount of EU funding toward urban centres. Valuable urban potentials include investment opportunities, knowledge and new technologies development, sustainable development and environment protection projects, etc. Following the EC commitment, new Act on regional development (end 2014), has stipulated the urban agglomerations for statistical and developmental purposes. The accurate urban agglomeration areas will be defined with separate regulation.[8] The new territorial structure shall induce the issues regarding partnership between all stakeholders on the urban agglomeration Ievel and creating joint objectives and projects suitable for application to EU funding.[9] 
Regarding these issues, the EElG represents a good possibility for cooperation between different stakeholders and linking them to partners from other countries with similar framework of interests for regional development. This could be particularly interesting considering notable differences between European regions level of development and bringing together partner experiences and knowledge which can contribute to improving lifelong learning participation rates in certain regions. EElG with clear objectives can facilitate establishing partnerships on projects of common interest. This is especially attractive to small and medium entrepreneurs, craftsmen and family farms, which can benefit from EElG membership by realizing its business objectives together with other partners.

The initiatives for establishing the EElG originate from regional similarities in neighbouring countries and their need for promoting certain destinations in order to improve the development of transport, entrepreneurship, tourism, agricultural production or cultural cooperation and heritage preservation. In spite of the fact that Regulation does not explicitly stipulate this option, often the initiatives were proposed from the region governments, which strive to strengthen the existing economic cooperation level, counting on mutual regional interests of entrepreneurs, civil society organizations and natural persons.

In order to ensure the strategic objectives fulfilment, it is important that public institutions, such as Local and Regional Self-government in Croatia, universities and others, become the member of an EElG. Furthermore, the participation of certain distinguished scientific, culture, sport and public figures, who can admit the EEIG as natural persons, can contribute to regional and transnational promotion of an EEIG. All members of an EEIG can act independently on new regional markets and simultaneously achieve additional benefits throughout the projects of common interest which can be developed in partnerships with other EElG members.

Recently adopted EU strategy for AdriaticIonian region could induce innovative models of cooperation between partners from counties and cities on both side of Adriatic Sea. [10] Accordingly, establishing an EElG can create additional value, as EElG's objectives will be linked to strategic priorities of macro-regions, especially toward improvements in transport, cultural, scientific and ecological partnerships based on similar interests in different member countries.

\section{European Economic Interest Grouping - advantages and risks}

The concept of an EElG has numerous possibilities:

- creating development projects and programmes for application to EU funds,

- strengthening regional entrepreneurial and other interests,

- entrepreneurs involvement in joint projects,

- regional cooperation of agricultural producers,

- regional tourism promotion,

- promotion of regional culture and heritage,

- knowledge and information dissemination,

- lifelong learning and

- new employment.

As the Regulation prescribed obligatory unanimous decision adoption between members, it can be consider as a risk for effective functioning of the organization with large number of members. This stipulation can be facilitated by allowing different number of votes per member as a statutory regulation. 
When the functioning of an EElG is being financed from member fees, specific risks can emerge regarding the cost control and the fact that members come from at least two EU countries, so presumably travel cost can be significant. Furthermore, the Regulation has clearly stated that all excessive costs shall be covered by all members. That stipulation gives preference to founder members which have more influence to the EElG manager[s], whereas other members have the same responsibilities, but less authority.

The Regulation prescribes that an EElG's are subject to national law of the Member state with registered office. Additional risks can occur from the fact that Member states have not harmonized the regulatory framework regarding EElG. As an example in Croatian legislation neither Companies Act nor Civil Organizations Act stipulates the definition of an EEIG.

In 2007 Croatian Parliament passed the Act on the Introduction of the European Company - Societas Europea [SE] and the EElG. [11] This Act regulates the conditions and means of implementation of the Regulation No 2137/85 and 2156/2001, and adjust the Company Act regarding EEIG and SE activities on the Croatian territory.

When considering joining some EElG, Croatian partners should be aware of risks which could emerge from subjecting to the national law of the Member state of registered EElG office. In order to avoid those risks Croatian partners should be well informed about the specific regulations of that Member state, as ignorance cannot exempt from individual responsibility of each EElG member.

Above mentioned clearly indicate wide possibilities of EElG implementation, but concurrently there are potential legal risks for unaware members.

\section{European experiences of EEIG activities}

There are several thousands of EElG's in the EU today, acting in various industries. Different abbreviations are being used for EElG: EWIV in Austria and Germany; EHzS in the Czech Republic, GElE in Italy, Ireland, Malta and Romania, while EElG is accepted in Great Britain, Latvia, Lithuania and Sweden.

Some of the well-known examples of an EElG's are presented hereinafter.

Association Relative à la Télévision Européenne [abbreviation: ARTE] is a European public television network, established back in 1991 from French and German partners. The main objective of ARTE is to ensure appropriate share of cultural content in order to promote unity and understanding between European nations. ARTE encourages creativeness in film, television and new media and it broadcast beyond EU [Africa and overseas]. [12]

European Advertising Lawyers Association Labbreviation: EALA], is an EElG established in 1988. Its objective is to promote the studying of European air transport legislation. Furthermore EALA provide the cooperation with the air transport sector for all interested participants. In 2014 EALA celebrated 26 years of its activity. [13]

European and Developing Countries Clinical Trials Partnership [abbreviation: EDCTP], is an example of an EEIG established with the mission of inventing new drugs and vaccines for severe diseases such as malaria, AIDS, tuberculosis and others. [14]

EURESA represents the grouping which promotes cooperation between 14 European insurance companies. The objective of their cooperation includes knowledge exchange, 
encouraging innovativeness and joint projects. These companies encompass over 22 million of insurance policies, with income of 21,2 billion Euros and 37.000 employees. Members of EURESA have established businesses in 10 Eu countries, as well as in Magreb [Africa) area. [15]

Abovementioned examples suggest that EElG can be established for various businesses and linked to specific type of promotional, educational and other services. For the time being only one initiative for EElG establishing has arrived to the potential Croatian partners from Italian founders of Peoples and Cities of Europe, GElE. Registered office of this EElG is in Italy and only one of Croatian cities will have the founder role. [16] the Peoples and Cities of Europe mission is to improve cooperation regarding youth cultural education and development, connections between European citizens and to introduce innovative projects in infrastructure, tourism, environment, culture and other. As this initiative is still in early phase, further details cannot be revealed at this point.

In the future other EElG initiatives can be expected in Croatia, so gathering the information about this type of cooperation should become an important task for Croatian entrepreneurs, public sector and other non-profit organizations.

\section{Conclusion}

The EU regional policy seeks to reduce structural disparities between EU regions by fostering balanced development throughout the $\mathrm{EU}$ and promoting real equal opportunities for all. These issues are extremely important for croatian development, especially regarding new opportunities of recently established macro-regions which include Croatian regions as well.
The EElG, represent the organization suitable for companies, institutions and natural persons, which according to Council Regulation, can be associated in order to carry out their economic and social missions.

In the process of considering the admission to EElG, an important issue involve careful familiarizing with legal framework of the country of registered EEIG office, as well as Council Regulation, where all rights and liabilities has been stipulated. While the 'old' EU member states have extensive experiences of establishing an EElG, this type of cooperation still represents novelty for most Croatian entrepreneurs and institutions. Therefore substantial risks of additional liabilities can emerge as a result of insufficient knowledge and experience with regulations incorporated in a foreign legal framework.

In spite of the shortage of available domestic cases of EElG establishment in the context of regional development, analysis of European experiences as well as the first-hand examination of an Italian initiative conducted in this paper, shows that EElG can provide an opportunity for promotion and business growth in new EU markets, as well as regional development throughout the EU macroregional strategies. Furthermore an EElG could enable an additional platform for wide range of economic, cultural, scientific, educational and environmental cooperation between numerous stakeholders. Considering lack of comprehensive national legal frame and lack of experience, careful approach is advisable to potential croatian partners. As EElG's could become an important element of Croatian regional development, vigilant evaluation of advantages and risks of Croatian partners involvement in EElg is crucial. 


\section{References}

[1] Zrilič, N. and Belošević Romac, S.: European Funds and Programs in the Function of the Regional and Local Development in Republic of Croatia, 3rd International Conference "Vallis Aurea" focus on: Regional Development, Proceedings, 5th October 2012, editor: Branko Katalinic, Pozega-Vienna, Croatia-Austria, 2012, p.p. 1163-1169

[2] Act on regional development of the Republic of Croatia, Narodne novine br. 153/09, Available at: http://WwW.zakon.hr

[3] The Strategy of regional development of the Republic of Croatia, 2011.-2013., Available at: http://Www.mrrfeu.hr

[4] Act on regional development of the Republic of Croatia, Narodne novine br. 147/14, Available at: http://www.zakon.hr

[5] Avaliable from: www.balticsea-regionstrategy.eu, www.danube-region.eu, www.adriaticionian.eu

[6] Council Regulation of European Economic Community (EEC) No. 2137/85, July 25, 1985, Available at: http://eur-lex.europa.eu/legal-content

[7] The Regulation Abstract, Available at: http://europa.eu/legislation

[8] Urban agglomeration, Available at: http://www.mrrfeu.hr

[9] The Strategy of regional development of the Republic of Croatia, 2011-2013., Available at: http://Www.mrrfeu.hr

[10] Adriatic-Ionian Initiative, Available at: http://Www.aii-ps.org

[11] Act on the Introduction of the European Company - Societas Europaea (SE) and the European Economic Interest Grouping [EElG], Available at: nttp://www. propisi.hr/print.php?id=7153
[12] Association Relative à la Télévision Européenne [Arte], Available

at:

http://www.arte.tv/static/c5/pdf/contrat_de_form ation.pdf

[13] European Advertising Lawyers Association [EALA], Available

at:

http://www. eala.aero/pagini/index.php

[14] EDCTP: European and Developing Countries Clinical Trials Partnership, Available at: http://www.edctp.org/About_EDCTP.2.0.htm|

[15] EURESA Icooperation between 10 European insurance companies], Available at: http://www.euresa.org/index.php?id=945\&l=1

[16] Peoples and Cities of Europe, Available at: http://www.trogir.hr/Grad Trogir/images/stories/Pozivi/P0zIVI_2013/5_sjednic aGV 